\title{
ELECTRO-RESISTANT BIOTEXTILE DEVELOPMENT BASED ON FIBER REINFORCEMENT WITH NANO PARTICLES
}

\author{
Arta Viluma-Gudmona, Inga Lasenko, Jaymin Vrajlal Sanchaniya, Andrejs Podgornovs \\ Riga Technical University, Latvia \\ arta.viluma.gudmona@rtu.lv, inga.lasenko@rtu.lv, jaymin.sanchaniya@rtu.lv
}

\begin{abstract}
Based on succinite superior biological and physical properties, elaborated biotextiles are excellent candidates of next generation multifunctional textiles. Here the thin, soft, and strong textile with superior abilities of electromagnetic interference shielding is prepared by technological composition of micro fibres reinforced with micro/nano particles: metal ( $\mathrm{Al} / \mathrm{Ag})$, silicium dioxide, resin fillers (succinite or its derivatives). The composite biotextile also exhibits an excellent electrical resistance property, and at the same time can be water and air vapour transmissible easily. It has been proven that due to the high electrical resistance of the biotextile, as well as based on the electronegative surface charge of the biotextile, an additional protective repulsive barrier is provided against nano-sized particles (viruses size 20-150 nm). By testing on the electrical conductivity and electrical resistance of the biotextile, it was proved: the static voltage test shows that biotextile material has a good antistatic property. Biotextile tested in tandem with synthetic materials, residual static voltage is recorded, which can be defined as the presence of a conductive and insulating material in the biotextile sample. Polarization index test results show the highest mobility of the dipoles of the biotextile (polarization index PI 3.03). This characterizes it as a good electrical insulating material, but its low insulation resistance limits its use at high voltages. This provides a new strategy to develop multifunctional textile materials. In the research result, the electrostatic interaction of a textile material and a negatively charged particle was modelled and analysed (particle size of the SARS-CoV-2 $=0.09$ $\mu \mathrm{m})$. The developed new technological method for analysing the protective properties of textile materials can be recommended as an additional test to the existing method for testing protective (filtering) materials with a charged surface.
\end{abstract}

Keywords: electro resistant material, nano particles with $\mathrm{Ag}, \mathrm{SiO}_{2}$ and succinite, COVID-19.

\section{Introduction}

The current pandemic, corona virus disease 2019 (COVID-19) expressed by extreme acute respiratory syndrome coronavirus-2 (SARS-CoV-2) has already caused severe public health problems and deaths around the world. Coronaviruses have been causing illness in birds and mammals for decades [1-4]. Coronaviruses are enclosed, single-strand RNA strains with mostly spherical in shape and diameters varying from 60 to $140 \mathrm{~nm}[5 ; 6]$.

Mostly during the COVID-19 pandemic, the use of masks and respirators as personal protective equipment (PPE) has earned a lot of publicity. Due to the lack of qualified PPE5 (e.g., N95 and P100 respirators), the general public and healthcare staff were forced to create realistic urgent alternatives out of commonly available materials [7]. The efficiency of improvised filter materials has been recorded by a number of research groups [8-11]. Their results have proven successful in the discovery of widely available materials capable of successful filtration against potentially virus-carrying particulate matter. Until now, these studies have typically assessed the filtration efficiency of a base filter media in an idealfit situation, in which materials are challenged inside a sealed container with no concern for leakage. Proper fit is critical, because the air permeability of the filter material influences where particles migrate in a poorly fitting mask, particularly for smaller particulates that can more easily follow air vectors around an imperfect fit $[12 ; 13]$.

It has been discovered that this virus can transmit to humans very easily, including during the incubation phase. SARS-surface CoV-2 stability is very close to that of SARS-CoV-1. The ribonucleoprotein matrix, which occupies the coronavirus lumen, accounts for a large portion of the volume in SARS-CoV-2 or SARS-CoV-1. Furthermore, 1/3 part of the positively and 2/3 part of the negatively charges are segregated locally in the crystal structure of SARS-CoV N-NTD (lumen) $[14 ; 15]$. As well, at neutral $\mathrm{pH}$ ( $\mathrm{pH}$ depends from the deposition medium), the most viral particles are negatively charged, because their isoelectric point is below 7. In this case, at neutral $\mathrm{pH}$ values, negatively charged viral particles will be significantly less adsorbed on the material (textile) surface due to electrostatic repulsion, since both virions and the substrate surface are negative charges [15].

For disinfecting water, a few new researches used the concept of electrostatic charges and an electric field over synthetic foam [15]. To kill the viruses, a layer of carbon Nano-tubes CNT is applied to a 
metallic filter and electroporation is performed. Many efficient circuits are recorded in the literature to generate such high step-up DC voltage from a very low DC supply. Similar to the use of mosquito swatters, such a circuit can be easily configured to minimize complexity. The negative terminal of the high voltage output may be grounded, while the positive terminal is attached to a metallic layer with a CNT coating or lithography to ablate Nano-grooves [16-19]. These metallic layers may be located on the most exposed sections of personal protective equipment (PPE), and thus the negative terminal is balanced through the shoes. The correct data can be established as a charging device in an open room, and the electrical circuit on the PPE does not need to be carried by the health staff.

Fibers are useful because the aim of randomly distributed discontinuous fibres is to bridge the crack's flanks, thereby providing some post-cracking "ductility." If the fibres in a matrix material are sufficiently strong and well-bonded, the FRC can carry significant stresses over a relatively wide strain region in the post-cracking stage (stage of visual crack formation and growing) [20;21]. One of the major engineering challenges over the last decade has been to create and mass-produce more effective materials in all industrial areas. At the moment, researchers are looking for new lightweight and reinforced metal-matrix composites; unique metallic-ceramic-matrix composites with reduced density, and revolutionary designs of reinforced metallic-polymer composites. In addition, revolutionary reinforced metals-crystals-polymer composite fibres with electromagnetic field resistance properties for office use [22-24].

It is known that the textile filters used in the mask for mechanical purification of the air, do not provide the constant purification efficiency for all sizes of virus particles in the range of the diameters from $0.1 \mu \mathrm{m}$ to $1 \mu \mathrm{m}$ (for example, from $0.1 \mu \mathrm{m}$ to $1 \mu \mathrm{m}$ efficiency decreases) [25]. For solution, electronegative properties of our proposed material were studied, which can be used as protective properties of masks as well, by attracting or repelling particles with an electrostatic charge with the mask material (typically electro spun plastic fibers). The particles with an electrostatic negative charge are more likely not to collide with the mask surface.

\section{Procedures of the examination}

In this experiment a voltmeter C50 (measurement system - electrostatic) and a multimeter EUROTEST XC EU MI 3152 [26] were used and comparative testing was performed on fabric samples with amber fibers (manufacturer UAB A Grupe, LT; mod. CL552T) and standard synthetic materials.

Testing is performed on a sample of $10 \times 10 \mathrm{~cm}$. A voltmeter connection diagram with a friction electrode is created with the electrodes located on opposite sides of the sample. Copper tapes are attached to a wooden base. The friction electrode consists of a log of $20 \mathrm{~mm}$ diameter wrapped in synthetic material. The voltmeter meets the requirements for testing anti-static surfaces in the electronics industry. The voltmeter specification meets the requirements of the standard IEC 61340-5-1:2016 Electrostatics - Part 5-1: Protection of electronic devices from electrostatic phenomena - General requirements as internal resistance of voltmeter $<1 \times 10^{6} \Omega$ at voltage $150 \mathrm{~V}$.

Testing environmental conditions were provided $(25 \pm 3) \% \mathrm{RH}$ and $23{ }^{\circ} \mathrm{C} \pm 2{ }^{\circ} \mathrm{C}$. All textiles and materials were conditioned at least for 48 hours before testing.

Table 1

Results of measured static voltage max value and residual voltage

\begin{tabular}{|c|c|c|c|}
\hline Material 1 & Material 2 & $\begin{array}{c}\text { Measured static } \\
\text { voltage max value }\end{array}$ & $\begin{array}{c}\text { Residual voltage } \\
\text { after 10 sec. }\end{array}$ \\
\hline Amber textile $(\mathrm{pH}=7.3)$ & Amber textile & Has not & Has not \\
\hline Amber textile $(\mathrm{pH}=7.3)$ & Polypropylene PP & $170 \mathrm{~V}$ & approximately 0 V \\
\hline Amber textile (pH=7.3) & Polyvinyl chloride PVC & $110 \mathrm{~V}$ & approximately 0 V \\
\hline Amber textile (pH=7.3) & Polyurethane PU & Has not & Has not \\
\hline Polypropylene PP & Polypropylene PP & $360 \mathrm{~V}$ & $40 \mathrm{~V}$ \\
\hline Polypropylene PP & Polyvinyl chloride PVC & $300 \mathrm{~V}$ & approximately 0 V \\
\hline Polyvinyl chloride PVC & Polyvinyl chloride PVC & $150 \mathrm{~V}$ & approximately 0 V \\
\hline
\end{tabular}

Also, for the fabric with amber fibres, a polarization index test was applied. This test is widely used in electrical installations to determine the state of insulation. It is based on the difference between the 
resistance of the material at the beginning and end of the test, and the polarization index shows the ability of charged particles to move in a dielectric under the influence of an electric field. Polarization current flows because of presence of impurities and moisture in dielectric material, the material becomes polar in nature. Therefore, when we apply high DC voltage across the dielectric material, the polar molecules (dipoles) try to align themselves in the direction of the applied electric field. During that period the molecules try to align along the electric field, a current will flow through the material because of the movement of dipoles along their axis. This current is called polarization current, and it lasts for a short time and as soon as the polar molecules align to the applied electric field, there will be no further movement of dipole and hence the polarization current will stop. It normally takes 10 minutes $(600 \mathrm{sec}$.) for the polarization current to become zero. Without measuring the currents, the measurement method used is based on a comparison of $\mathrm{M} \Omega$ meter readings taken 60 and 600 seconds after the start of the test. Testing of samples of materials was carried out according to the method of checking the insulation of electrical installations according to the standard IEC 60364-6:2016 Low voltage electrical installations - Part 6: Verification. Testing voltage was $1000 \mathrm{~V}$ for all materials.

Table 2

Results of polarization index test

\begin{tabular}{|c|c|c|c|}
\hline Material & R60, M $\Omega$ & $\mathrm{R600,} \mathrm{M} \Omega$ & PI (polarization index) \\
\hline Amber textile & 645 & 1954 & 3.03 \\
\hline Polyvinyl chloride PVC & 6248 & 9567 & 1.53 \\
\hline Polypropylene PP & 957 & 1468 & 1.53 \\
\hline Polyurethane PU & 2445 & 6243 & 2.55 \\
\hline
\end{tabular}

Discussion of the results will be done below.

\section{Mathematical model of interaction of electric fields}

To assess the interaction of electric fields: a charged particle (for example, a virus) and the surface of a textile material with a negative charge (Fig. 1), a mathematical model was created that reflects their mutual interaction, and also the obtained values of their electric fields were taken for modelling.

The textile material (Fig. 1) includes the following yarn/fibre composition and textile structure, see Table 3. The amber fibre (7.8 Tex 12f, am_in) is composite, the matrix of the amber fibre is polyamide 66 (PA66 CS29 with $0.3 \%$ of SiO2), the fibre is obtained by extrusion (LOY) from a composite polymer mass, which includes: amber powder (concentration 5\%, particle size from $400 \mathrm{~nm}$ to 3 microns), amber particles are localized in the upper part on the surface of filaments, the total area of filament coverage with amber particles is $20 \%$; the silver powder, in the form of heterogeneous inclusions, which are conglomerates of silver particles (concentration $0.5 \%$, particle size from $400 \mathrm{~nm}$ to $800 \mathrm{~nm}$ ) are localized inside filaments in the form of nanofibers.

Table 3

Physical and mechanical indexes of textile material

\begin{tabular}{|l|c|}
\hline \multicolumn{1}{|c|}{ Parameters } & Value \\
\hline Width of fabric, $\mathrm{cm}$ & $150 \pm 2$ \\
\hline Surfacial density, $\mathrm{g} \cdot \mathrm{m}^{2}$ & $130 \pm 9$ \\
\hline Number of threads in $10 \mathrm{~cm}$ & $205 \pm 4$ \\
\hline In warp & $170 \pm 5$ \\
\hline In weft & Linear density of yarns, Tex \\
\hline \multicolumn{2}{|c|}{ B28 Tex, linen } \\
\hline In warp & $\begin{array}{c}28 \text { Tex Cotton twisted with 7.8 Tex } \\
\text { amber fibers; twist: } 160 \mathrm{TR} / \mathrm{m}\end{array}$ \\
\hline In weft & Linen - 80\%; others $-20 \%$. \\
\hline Composition of flax, \% & 274 \\
\hline \multicolumn{2}{|c|}{ Fabric breaking loading, N not less } \\
\hline In warp & 274 \\
\hline In weft &
\end{tabular}


Table 3 (continued)

\begin{tabular}{|l|c|}
\hline \multicolumn{1}{|c|}{ Parameters } & Value \\
\hline \multicolumn{1}{|c|}{ Dimensional change after washing, not more (in\%) } \\
\hline \multicolumn{1}{|c|}{ In warp } & 4.0 \\
\hline \multicolumn{1}{|c|}{ In weft } & 7.0 \\
\hline Factual humidity, not more (in\%) & 9 \\
\hline $\begin{array}{l}\text { Quantity of free formaldehyd, } \mu \mathrm{g} / \mathrm{g} \\
\text { (ppm) not more }\end{array}$ & 75 \\
\hline Air conductibility, L·m-2.s-1 & $503 \pm 85 \mathrm{~L} \cdot \mathrm{m}^{-2} \cdot \mathrm{s}^{-1}$ \\
\hline Hydroscopy, \% & $7.82-10.59$ \\
\hline
\end{tabular}
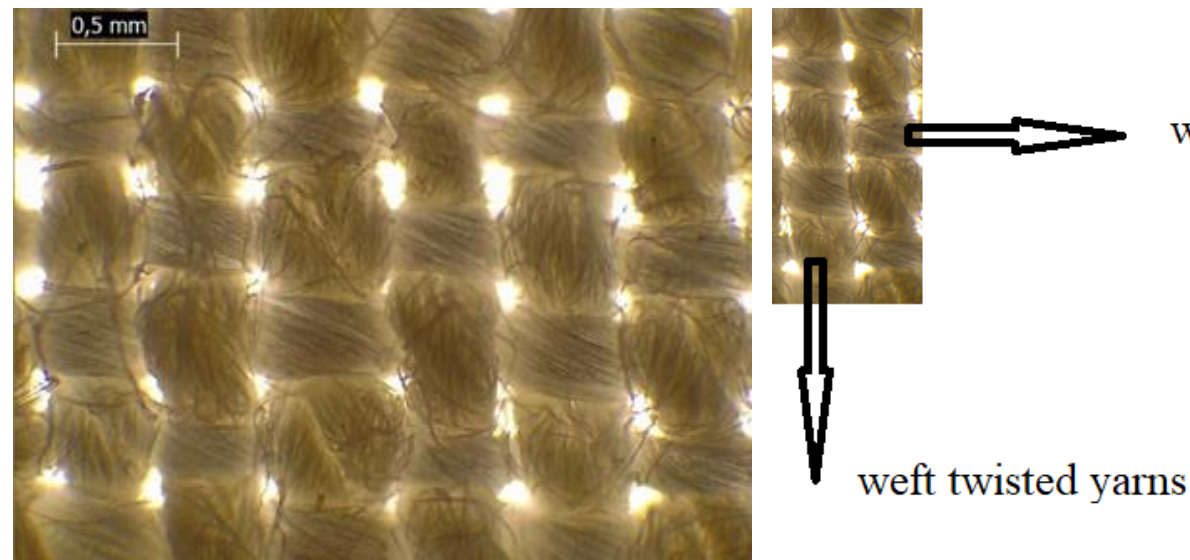

Fig. 1. Weaving material (plain weave) (Microscope Leica DMI 6000 B (Leica) (x40))

The calculation was carried out by the finite element method (FEM) QuickField program [27]. The problem of electrostatics of interaction of electric fields was solved. The model of the textile material (Fig. 1) is an area with given boundary conditions, and it is necessary to represent the textile material, reflecting its properties - morphological and electrical, respectively.

Fig. 2 shows the mathematical model reflecting the mutual interaction of a charged particle and the surface of the textile material with a negative charge, where $5 \mathrm{~h}(\mathrm{~mm})$ is the distance from the fourth edge of the textile material to a point charged particle, $\mathrm{h}(\mathrm{mm})$ is the average value of the clearance in the textile material $(0.1 \mathrm{~mm}$, from Fig. 1$)$.

The boundary conditions (numbering clockwise, Fig. 2) were set in the QuickField program and are shown in Fig. 2.

It is assumed that the simulated surface charged textile material depends on the change of the field voltage $0.5-10 \mathrm{~V}(10 \mathrm{~V}$ boundary condition on 4 edge $)$.

As a first approximation, the distance from a charged particle to a textile material (protective textile mask) is taken arbitrarily and is equal to $5 \mathrm{~h}(\mathrm{~mm})$, without taking into account the gravity and other actions of forces (velocity of a charged particle and its mass), where $\mathrm{h}(\mathrm{mm})$ is the average value of the clearance in the textile material $(0.1 \mathrm{~mm})$. A charged particle is represented by a chiselled charge, where the total surface charge of the virus is $-5 \mathrm{eV}$ [28].

It is known that the voltage $(\mathrm{U})$ of the electric field is the potential difference between two points of this field, which is characterized by the work (A) performed by the force of the field on the movement of charged particles between two points of the field.

The task of the modelling is to determine the repulsive forces of the electrostatic field of the textile material, acting on an electrically charged point particle.

The modeling results of the regarded objects are presented in the following Fig. 3-9. 


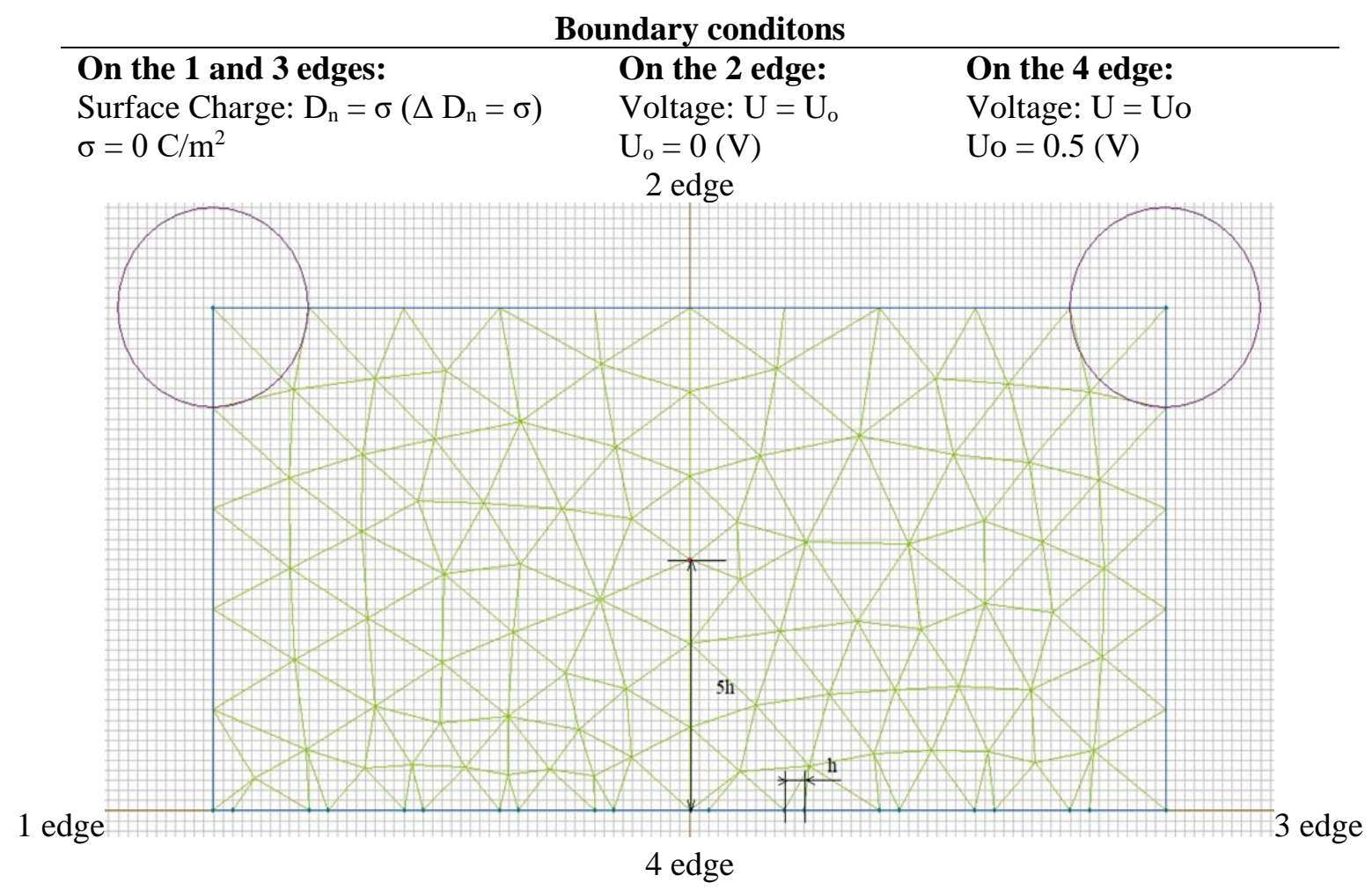

Fig. 2. Mathematical model reflecting the mutual interaction of a charged particle

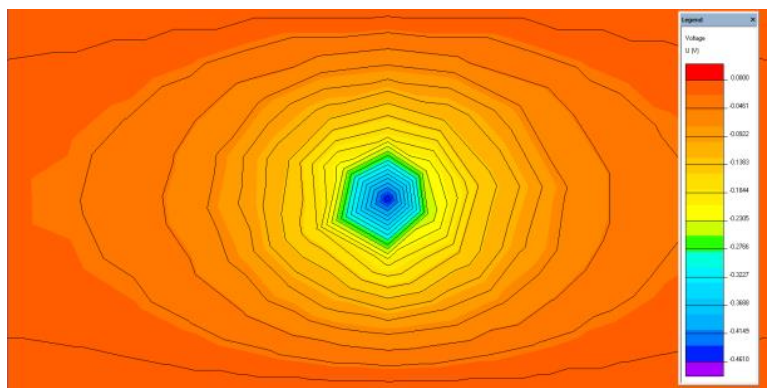

Fig. 3. General scene distribution force lines of the model (textile material $\div$ electrically charged particle).

At the voltage of the electric field $0 \mathrm{~V}$ on the 4 edge (lower horizontal edge of the textile material), the force effect of the field on the particle is $f=1.1868 \mathrm{e}-12(\mathrm{~N})$

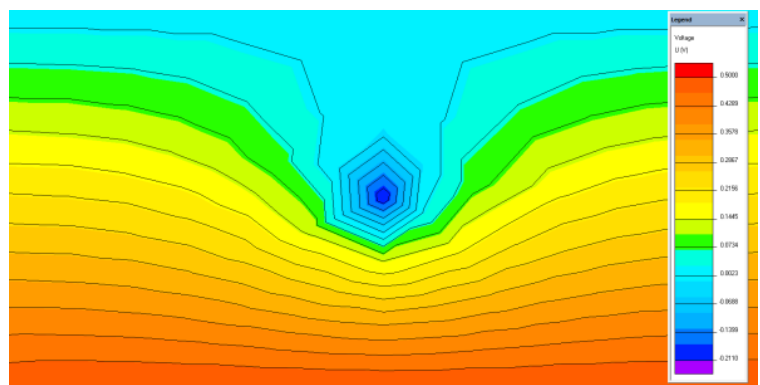

Fig. 4. Distribution force lines of the model (textile material $\div$ electrically charged particle) at the voltage of the electric field 0.5 $\mathrm{V}$. At the voltage modelling of the electric field $0.5 \mathrm{~V}$ on the 4 edge (lower horizontal edge of the textile material), the force effect of the field on the particle is increased and constitutes $f=1.2336 \mathrm{e}-12(\mathrm{~N})$

As shown in Fig. 4, a point charge being at a close distance from the surface of the textile material (the ratio of the distance between the yarns/fibers to the distance for the electrically charged particle) distorts the electrostatic scene of the field. The force lines of the field tend to repel a point charged particle from the textile material, so to align the force surface of the field (2D), acting with a force $f=1.2336 \mathrm{e}-12(\mathrm{~N})$.

With further modelling, successively changing the voltage of the electric field at the lower edge of the textile material, a uniformly distribution of the force lines of the field was obtained, acting from the side of the charged textile material on the point charge, reflected in Fig. 5-9.

The simulation results of the modelling have shown (as follows from Fig. 4-Fig. 9): having a small charge of the external electric field (acting from the textile material), it effectively has an effect on the point charge. At voltage changes of the electric field from 0.5 to $10 \mathrm{~V}$ at edge 4 (lower horizontal), the repulsive field strength (from the textile material to a point charged particle) increases by a factor of 275. 


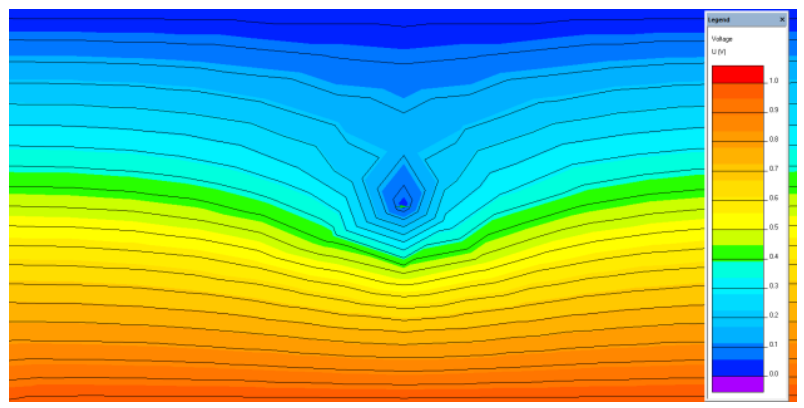

Fig. 5. Distribution force lines of the model at the voltage of the electric field $1 \mathrm{~V}$. At the voltage modelling of the electric field $1 \mathrm{~V}$ on the 4 edge (lower horizontal edge of the textile material), the force effect of the field on the particle is $f=3.0269 \mathrm{e}-12(\mathrm{~N})$

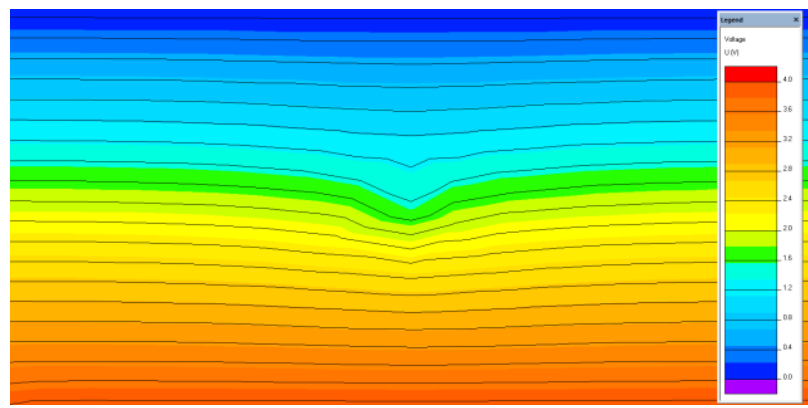

Fig. 7. Distribution force lines of the model at the voltage of the electric field $4 \mathrm{~V}$. At the voltage modelling of the electric field $4 \mathrm{~V}$ on the 4 edge (lower horizontal edge of the textile material), the force effect of the field on the particle is $f=5.107 \mathrm{e}-11(\mathrm{~N})$

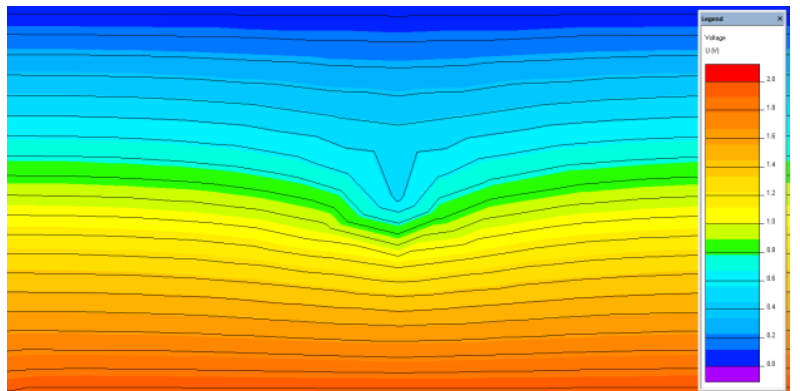

Fig. 6. Distribution force lines of the model at the voltage of the electric field $2 \mathrm{~V}$. At the voltage modelling of the electric field $2 \mathrm{~V}$ on the 4 edge (lower horizontal edge of the textile material), the force effect of the field on the particle is $f=1.1952 \mathrm{e}-11(\mathrm{~N})$

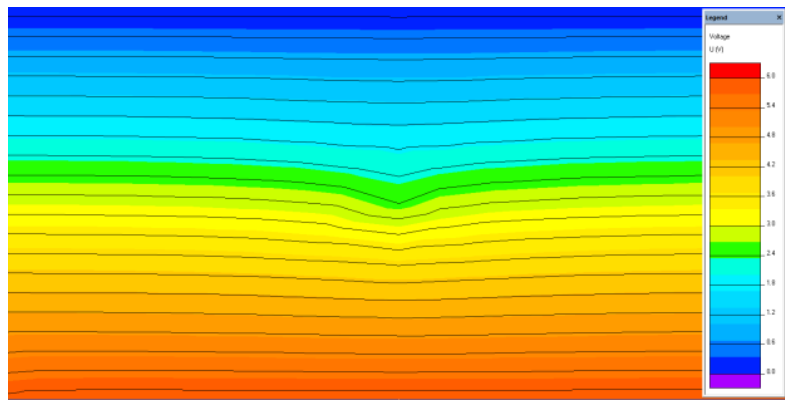

Fig. 8. Distribution force lines of the model at the voltage of the electric field $6 \mathrm{~V}$. At the voltage modelling of the electric field $6 \mathrm{~V}$ on the 4 edge (lower horizontal edge of the textile material), the force effect of the field on the particle is $f=1.1852 \mathrm{e}-10(\mathrm{~N})$

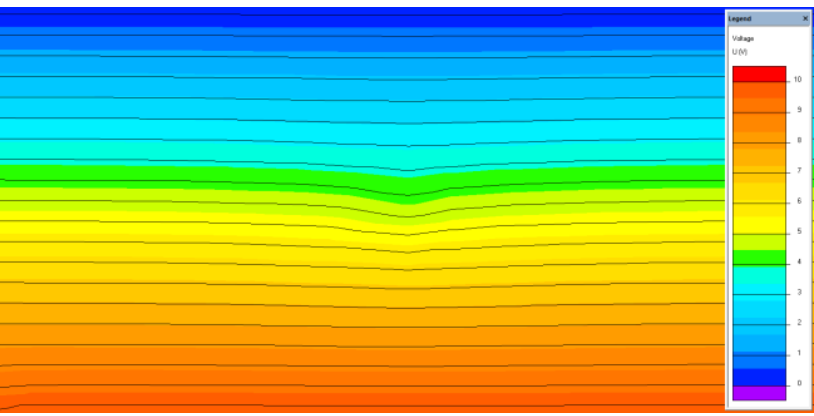

Fig. 9. Distribution force lines of the model at the voltage of the electric field $10 \mathrm{~V}$.At the voltage modelling of the electric field $10 \mathrm{~V}$ on the 4 edge (lower horizontal edge of the textile material), the force effect of the field on the particle is $f=3.3843 \mathrm{e}-10(\mathrm{~N})$

The values of the dependence of the repulsive force acting on a point charge from the simulated voltage on the textile material surface are summarized in Table 4 and shown in Fig. 10.

Thereby, as show in Fig. 10, with an increasing of the potential of the textile material, the distribution of force lines is aligned, which is due to the excessive potential textile material, relatively of the small point charge. It is not necessary to consider the peak value of $150 \mathrm{~V}$ of the field voltage, but it is only necessary to provide an average value of the field voltage in the range of up to $10 \mathrm{~V}$ (a necessary and sufficient condition). 
Values of the repulsive force acting on a point charge from the simulated voltage

Table 4 on the surface of the textile material

\begin{tabular}{|c|c|c|}
\hline $\begin{array}{c}\text { Voltage of the electric field } \\
(\mathbf{U}), \mathbf{V}\end{array}$ & $\begin{array}{c}\text { Repulsive force of the field } \\
(\mathbf{F}), \mathbf{N}\end{array}$ & $\begin{array}{c}\text { Repulsive force of the field } \\
(\mathbf{F}) \mathbf{p N}(\mathbf{1 E}+\mathbf{1 2})\end{array}$ \\
\hline 0 & $1.1868 \mathrm{e}-12$ & 1.19 \\
\hline 0.5 & $1.2336 \mathrm{e}-12$ & 1.23 \\
\hline 1 & $3.0269 \mathrm{e}-12$ & 3.03 \\
\hline 2 & $1.1952 \mathrm{e}-11$ & 11.95 \\
\hline 4 & $5.107 \mathrm{e}-11$ & 51.07 \\
\hline 6 & $1.1852 \mathrm{e}-10$ & 118.52 \\
\hline 10 & $3.3843 \mathrm{e}-10$ & 338.43 \\
\hline
\end{tabular}

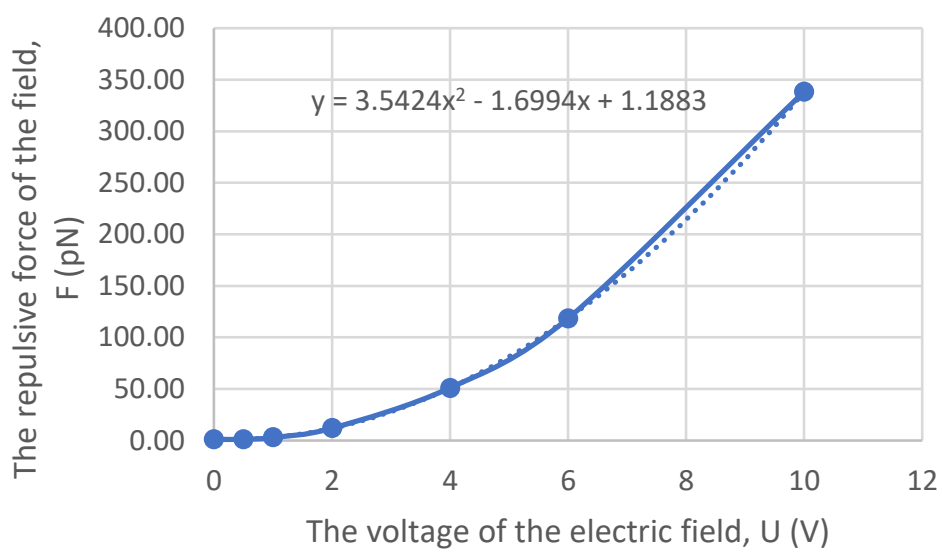

Fig. 10. Graph dynamic of the change of the value of the repulsive force, acting on a point charge, from the simulated voltage on the surface of the textile material

\section{Discussion of the results}

The static voltage test shows that textile with amber fibres has a good antistatic property. When textile with amber fibres tested in tandem with synthetic materials, residual static voltage is recorded, which can be defined as the presence of a conductive and insulating material in the amber textile sample. The observed measured static voltage max value increased (in the first second of measurement) from $110 \mathrm{~V}$ till $360 \mathrm{~V}$ in all combinations of materials (indicated in Table 1), with the exception of amber textile and polyurethane samples, where the static voltage value was 0 . However, the residual voltage after $10 \mathrm{sec}$. was not observed in all samples, except for double polypropylene sample and was equal $40 \mathrm{~V}$.

Polarization index test results show the highest mobility of the dipoles of the material with amber fibres PI $=3.03$, compared with polyvinyl chloride ( 2 times less), polypropylene ( 2 times less) and polyurethane materials (1.2 times less). This characterizes as a good electrical insulating material, but its low insulation resistance limits its use at high voltages.

As shown by the simulation results (Fig. 3-Fig. 9), there is no need to simulate a field voltage higher than $10 \mathrm{~V}$, since the repulsive force of the electric field acting on an electrically charged particle increases in 300 times.

It should be noted that in real conditions, since the virus has a negative charge $(-5 \mathrm{eV})$, it allows to be attracted to positively charged surfaces. It gives the electrically charged particle additional acceleration and change the path towards the surface. Consideration of modelling the interaction of an electrically charged particle with an electric field of the textile material in dynamics is the next stage of scientific work.

It is known that textile materials based on natural raw materials do not accumulate the charge, compared with the synthetic materials. The composite amber fibres are capable of accumulating the 
charge, since the basis (matric) of the fibre is polymer PA66, where the electronegative charge provides the amber particles, which are an integral part of the fibre (results of the experiments, Tables 1 and 2).

In addition, the synthetic materials, also have electrical conductivity. The electrical conductivity of the material makes it possible to equalize the potential difference in the textile material and not create an uncomfortable state when using clothes (adhesion of dust particles, spark discharge in time of the mechanical friction material by material). In this way, on the fabrics for protective textile materials it is possible to create a potential that creates additional forces of repulsion of charged particles from textile materials, using the knowledge of the presence of the charge particles (size, for example, as viruses, 20$150 \mathrm{~nm})$.

In the study (Table 1), pairs of textile materials with such charge were identified (Table 1, with the exception of amber textile and PU pairs). Also recommended pairs are not revealed, due to residual charge (Table 1, PP + PP pairs). In turn, to assess the forces of electrostatic interaction of an electrically charged particle and textile materials, the method of mathematical modelling was applied. As a result, a dependence was obtained and described by a polynomial of the second degree with a high degree of correlation. This made it possible to carry out preliminary analytical calculations for the selection of pairs of textile materials that provide electrostatic protection against electrically charged particles.

As follow from [15] the neutral $\mathrm{pH}$ ( $\mathrm{pH}$ depends from the deposition medium), the most viral particles are negatively charged, because their isoelectric point is below 7. In this case, at neutral $\mathrm{pH}$ values, negatively charged viral particles will be significantly less adsorbed on the material (textile) surface due to electrostatic repulsion, since both virions and the substrate surface are negative charges (tested, amber-containing the textile materials (Table 1, samples 1-4) have the neutral $\mathrm{pH}$, their $\mathrm{pH}$ is 7.3). It also proves the right direction for the research described in this article.

The developed the new technological method for analysing of the protective properties of textile materials can be recommended as an additional test to the existing method for testing protective (filtering) materials with a charged surface (based on the European standard EN 143 + AC:1990; 2002 Dec).

\section{Conclusions}

1. Based on the QuickField program, the electrostatic interaction of a textile material and a negatively charged particle was modelled and analysed (particle size of the SARS-CoV-2 $=0.09 \mu \mathrm{m}$ ).

2. It has been proved (under the necessary condition of the presence of objects with electrically charged surfaces) that the resulting electric potential (in time of mechanical friction) on the surface of the textile material contributes to the formation of forces that repel negatively charged particles.

3. The developed the new technological method for analysing of the protective properties of textile materials can be recommended as an additional test to the existing method for testing protective (filtering) materials with a charged surface.

\section{Acknowledgements}

This research was supported by the Riga Technical University Doctoral Grant programme and the Project "Development and behaviour analysis of novel textile composite/metal joints with enhanced mechanical properties" lzp-2019/1-0357 ID: 4277, 2020-2023.

\section{Reference}

[1] Perlan S., Fehr A.R. Coronaviruses: an overview of their replication and pathogenesis, Humana Press, 2015, pp. 1-23.

[2] Kahn J.S., et.al. History and recent advances in coronavirus discovery, Pediatr Infect Dis J, 2005, pp. 223-227.

[3] Mawditt K., Sharma M., Cavanagh D., et. al. Detection of a coronavirus from Turkey poults in Europe genetically related to infectious bronchitis virus of chickens, Avian Pathol, vol. 30, 2001, pp. 355-368.

[4] Teixeira B., Luvizotto R., et. al. Detection of Turkey coronavirus in commercial Turkey poults in Brazil., Avian Pathol, vol. 36, 2007, pp. 29-33.

[5] Whitley R., Hayden F., Richman D. Clinical virology. 4th ed., US: John Wiley \& Sons, 2016. 
[6] Neuman B., Adair B., et. al. Supramolecular architecture of severe acute respiratory syndrome coronavirus revealed by electron cryomicroscopy, J Virol, no. 80, 2006, pp. 7918-7928.

[7] Kaur H. and Luhby T. People around the country are sewing masks. And some hospitals, facing dire shortage, welcome them., CNN, [Online]. Available: https://edition.cnn.com/2020/03/24/us· $\mathbf{s}^{-}$ ${ }^{1}$ ewing-groups-masks-coronavirus-wellness-trnd/index.html. [Accessed Monday March 2021].

[8] Konda A. et. al. Aerosol Filtration Efficiency of Common Fabrics Used in Respiratory Cloth Masks, ACS Nano 2020, no. 14, p. 6339.

[9] Zangmeister C. D., Radney J. G., Vicenzi E. P., Weaver J. L. Filtration Efficiencies of Nanoscale Aerosol by Cloth Mask Materials Used to Slow the Spread of SARS-CoV-2, ACS Nano 2020, no. 14 , p. 9188.

[10]Zhao M.,et. al. Household Materials Selection for Homemade Cloth Face Coverings and Their Filtration Efficiency Enhancement with Triboelectric Charging, Nano Lett. 2020, no. 20, pp. 55445552.

[11] Davies A., et. al. Testing the Efficacy of Homemade Masks: Would They Protect in an Influenza Pandemic?, Disaster Med. Public Health Prep, no. 7, 2013 pp. 413-418.

[12] Imani R. J., Ladhani L., Pardon G., Robert E. The Influence of Air Flow Velocity and Particle Size on the Collection Efficiency of Passive Electrostatic Aerosol Samplers, Aerosol Air Qual. Res., no. 19, 2019, pp. 195-203.

[13] Singh P. Airflow and Particle Transport Prediction through Stenosis Airways., Int. J. Environ. Res. Public Health, no. 17, 2020, p. 1119.

[14] Morris D. H., et. al. Aerosol and surface stability of SARS-CoV-2 as compared with SARS-CoV1, N Engl J Med, vol. 16, 2020, pp. 74-81.

[15] Saikatendu K.S., et. al. Ribonucleocapsid formation of severe acute respiratory syndrome coronavirus through molecular action of the $\mathrm{N}$-terminal domain of $\mathrm{N}$ protein, $\mathrm{J}$ Virol, vol. 8, no. 81, 2006, pp. 3913-3921.

[16] Qianqian Y., et. al. Negatively charged residues in the endodomain are critical for specifc assembly of spike protein into murine coronavirus, Virology, vol. 1, no. 442, 2013, pp. 74-81.

[17] Liu C., et. al. Conducting nanosponge electroporation for afordable and high-efciency disinfection of bacteria and viruses in water, Nano Lett, vol. 13, no. 9, 2013, pp. 4288-4293.

[18] Liu C., et. al. Static electricity powered copper oxide nanowire microbicidal electroporation for water disinfection, Nano Lett, vol. 14, no. 10, 2014, pp. 5603-5608.

[19] Fardoun I. E. Ultra sSep-Up DC-DC converter with reduced switch, IEEE International Conference on sustainable energy technologies, 2008, pp. 425-430.

[20] Krasnikovs A., et. al. Fiberconcrete with Non-Homogeneous Fibers Distribution, Proc. 9th Int. Sci. Pract. Conf. Environment. Technol. Resour., vol. 2, 2013, pp. 67-71.

[21] Lusis V. et. al. Effect of short fibers orientation on mechanical properties of composite material fiber reinforced concrete, J. Civ. Eng. Manag, vol. 23, no. 8, 2017, pp. 1091-1099.

[22] Lyashenko I., et. al. Manufacturing of Amber Particles Suitable for Composite Fiber Melt Spinning, The Journal of Latvian Academy of Sciences, vol. 70, 2016, pp. 51-57.

[23] Lyashenko I., et. al. Application of amber filler for production of novel polyamide composite fiber, Textile Research Journal, vol. 86(20), 2016, pp. 2127-2139.

[24] Lyashenko I., Grauda D., et. al. Amber Particles as Living Plant Cell Markers in Flow Cytometry, The Journal of Latvian Academy of Sciences, vol. 69, 2015, pp. 77-81.

[25] Mechanisms of Filtration for High Efficiency Fibrous Filters, TSI Incorporated, 2020.

[26] Metrel homepage. [online] [20.03.2021]. Available at: https://www.metrel.si.

[27] QuickField Student Edition [online] [20.03.2021]. Available at: https://quickfield.com/free_soft.htm.

[28] Liu L., Feng G., et. al. Electron beam irradiation on novel coronavirus (COVID-19): A MonteCarlo simulation, IOP Publishing Public Health Emergency Collection,2020, vol. 29.

[29] Beeching M. J., et. al. BMJ Best Practice, BMJ Best Topic Practice, London, 2020. 